\title{
Current and future trends in coagulation management for congenital heart surgery
}

\author{
Erin A. Gottlieb, MD, and Dean B. Andropoulos, MD, MHCM
}

\footnotetext{
From the Arthur S. Keats Division of Pediatric Cardiovascular Anesthesiology and Department of Anesthesiology, Texas Children's Hospital; and Department of Anesthesiology Baylor College of Medicine, Houston, Tex

Received for publication Sept 14, 2016; revisions received Nov 9, 2016; accepted for publication Nov 15, 2016; available ahead of print March 14, 2017.

Address for reprints: Erin A. Gottlieb, MD, 6621 Fannin WT 17-417B, Houston, TX 77030 (E-mail: eagottli@ texaschildrens.org).

J Thorac Cardiovasc Surg 2017;153:1511-5

$0022-5223 / \$ 36.00$

Copyright (C) 2017 by The American Association for Thoracic Surgery

http://dx.doi.org/10.1016/j.jtcvs.2016.11.075
}

It is well known among surgeons, anesthesiologists, and intensivists caring for pediatric patients undergoing cardiac surgery that perioperative bleeding and blood product transfusion are significant challenges. Both patient and operative factors influence the risk of bleeding in this population. Effective and efficient coagulation management increasingly has become important, as the risks of transfusion on short- and long-term outcomes have become evident. Transfusion is associated with both nonimmune- and immune-mediated reactions including infection, hemolytic reactions, allergic reactions, transfusion-related acute lung injury, transfusion-associated graft-versus-host disease, and transfusion-related immunomodulation. Increased morbidity and mortality are associated with red cell transfusion in the pediatric cardiac surgery population. ${ }^{1}$ Patients with congenital heart disease who undergo multiple operations with repeated exposures to blood products generate alloantibodies, which can become problematic should the patient eventually require cardiac transplantation. Allosensitization leads to longer waiting time and pretransplant mortality, as well an increased risk of early death after transplant. ${ }^{2,3}$

It also is clear that wide variation in transfusion strategy exists between centers, ${ }^{4}$ and therapy for postbypass coagulopathy largely has been empiric. ${ }^{5}$ Much of this variation is attributable to the patient population, the surgical procedure, and the need for and conduct of cardiopulmonary bypass (CPB). The population of pediatric patients undergoing surgery for congenital heart disease is heterogeneous. These patients vary by age, size, presence and degree of cyanosis, presence and degree of polycythemia, preoperative anticoagulation, and other comorbidities. Surgical procedures differ in the need for CPB, the degree of hypothermia, the use of techniques such as selective cerebral perfusion or deep hypothermic circulatory arrest, and whether the patient has undergone a previous sternotomy. In addition, the bypass circuit priming volumes produce different degrees of hemodilution and dilution of coagulation factors depending on the size of the patient, with

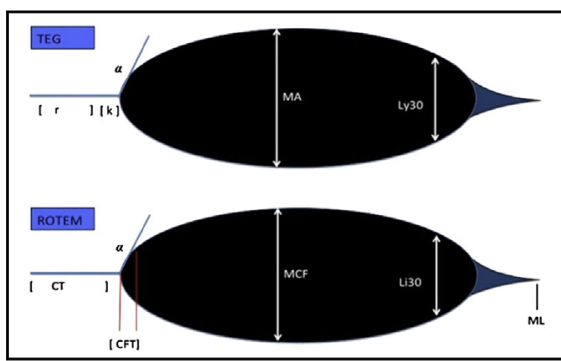

Thromboelastography versus rotational thromboelas tometry, emphasizing the similarities between the 2 methods

Central Message

Trends in the treatment of postbypass coagulopathy in pediatric patients include goaldirected transfusion algorithms, point-of-care testing, and factor concentrates.

See Editorial Commentary page 1516

neonates experiencing the greatest dilutional effect. A similar effect is seen in patients undergoing a partial or full exchange transfusion for sickle cell disease. Multiple management strategies must exist to care for very different patients undergoing a variety of procedures, making standardization of care difficult.

Current areas of interest include the use of fresh whole blood to prime the CPB circuit, the use of antifibrinolytics, the use of intraoperative point-of-care (POC) testing, the role of goal-directed transfusion algorithms or guidelines, the emerging role of factor concentrates in the treatment of postbypass coagulopathy, and antithrombin supplementation in neonates and infants for CPB.

\section{FRESH WHOLE BLOOD}

The use of fresh whole blood (less than 48 hours from donation to transfusion) has been demonstrated to reduce bleeding in patients younger than 2 years old undergoing complex operations for congenital heart disease, ${ }^{6}$ and its use recently has been reported to reduce the number of blood donor exposures. ${ }^{7}$ Other studies, however, have not shown a benefit of priming with fresh whole blood compared with reconstituted blood (packed red blood cells and fresh frozen plasma). ${ }^{8}$ Gruenwald and colleagues 9 compared clinical outcomes in patients receiving reconstituted fresh whole blood (red cells, plasma, and platelets from a single donor) versus standard component therapy; findings included decreased chest tube output at 24 hours, 
decreased inotropic score at 24 hours, and decreased time to extubation with reconstituted fresh whole blood. Other advantages with reconstituted whole blood were greater platelet count at the end of bypass, a decrease in donor exposures, and younger age of blood products.'

Significant challenges exist in obtaining fresh whole blood for pediatric cardiac surgery. Jobes and colleagues ${ }^{7}$ emphasize that careful planning and communication between the donation center, blood bank, and surgical service is required to make these products available. Leukocyte reduction is now available for fresh whole units, which should decrease allosensitization. ${ }^{8}$ Reconstituted fresh whole blood may preserve platelet function, because these units are isolated and stored at room temperature. The platelets in fresh whole blood may have decreased function due to storage at $4^{\circ} \mathrm{C}^{1,9}$

\section{ANTIFIBRINOLYTICS}

Aprotinin, a serine protease inhibitor, and epsilonaminocaproic acid (EACA) and tranexamic acid (TXA) are efficacious in reducing bleeding and transfusion in pediatric patients undergoing cardiac surgery. After aprotinin became unavailable in most institutions, many centers replaced it with EACA or TXA. Dosing strategies are variable for each drug and are not always based on pharmacokinetic data. ${ }^{10}$ The dosing regimen for EACA used at Texas Children's Hospital is a loading dose of $75 \mathrm{mg} / \mathrm{kg}$ to the patient, $75 \mathrm{mg} / \mathrm{kg}$ to the bypass prime, and a $75 \mathrm{mg} / \mathrm{kg} / \mathrm{h}$ infusion, based on pharmacokinetic data from Ririe and colleagues. ${ }^{11}$ Recently, neonatal EACA dosing has been modified to reflect reduced clearance with a loading dose of $40 \mathrm{mg} /$ $\mathrm{kg}$, an infusion of $30 \mathrm{mg} / \mathrm{kg} / \mathrm{h}$, and a concentration of $100 \mathrm{mg} / \mathrm{L}$ in the bypass prime. ${ }^{12}$

TXA dosing schema based on pharmacokinetic modeling and designed to produce a low, intermediate, or high plasma concentrations in neonates and infants $<2$ months of age, infants 2 to 12 months, and children $>12$ months of age recently have been reported. ${ }^{13}$ These dosing recommendations reflect age-related differences in clearance, and like the neonatal dosing modification for EACA, are designed to produce a specified concentration in the bypass prime, rather than a weight-based bolus. ${ }^{10}$

Although all 3 antifibrinolytics reduce bleeding and transfusion in pediatric cardiac surgery patients, both EACA and TXA are reported to be associated with increased bleeding compared with aprotinin, eg, increased rates of administration of recombinant activated factor VII (rFVIIa), surgical re-exploration, and transfusion. ${ }^{14,15}$

\section{MONITORING OF COAGULATION STATUS}

Coagulation status can be analyzed with laboratory tests and POC tests. Standard laboratory tests include a platelet count, prothrombin time, partial thromboplastin time, and fibrinogen concentration. The laboratory tests are helpful for defining coagulopathy, but results can take so much time that they are not useful for guiding treatment. POC tests include the activated clotting time (ACT), used to monitor heparin effect, thromboelastography (TEG), and rotational thromboelastometry (ROTEM; TEM Systems, Inc, Research Triangle Park, NC), used to identify and characterize coagulopathy, and platelet function tests, including the Sonoclot analyzer (Sienco, Inc, Boulder, Colo), PFA100 (Siemens Medical Solutions USA, Inc, Malvern, Pa), and MultiPlate (Roche Diagnostics International, Ltd, Rotkreuz, Switzerland) platelet aggregometer. ${ }^{5}$ The advantage of POC tests is that the result and/or tracing is available in real time. The ACT is easy to perform, inexpensive, and provides a simple way to monitor the effects of heparin.

TEG and ROTEM are being used increasingly to determine the nature of the coagulopathy (Figure 1). Both tests provide a real-time assessment of the multiple components of hemostasis including platelet activity, coagulation factors, fibrinogen, and fibrinolysis. Both TEG and ROTEM have been demonstrated to decrease transfusion requirements in pediatric cardiac surgery. ${ }^{16-18}$ Furthermore, specific ROTEM analysis during CPB before hemoconcentration allows the earlier detection of coagulation abnormalities. ${ }^{19}$ These tests can lead to improved goal-directed planning and therapy. Platelet function tests have not been used widely in pediatric cardiac surgery. More importantly, these POC tests provide direction for treatment, instead of empiric therapy with platelets or cryoprecipitate, as has been standard practice. ${ }^{20}$

\section{GOAL-DIRECTED TRANSFUSION THERAPY}

Goal-directed transfusion algorithms have been used extensively in adult cardiac surgery and have been demonstrated to decrease transfusion, improve clinical outcomes, and standardize practice. Many of these algorithms are based on POC tests such as TEG or ROTEM. ${ }^{21}$ Goaldirected algorithms also have been described for pediatric
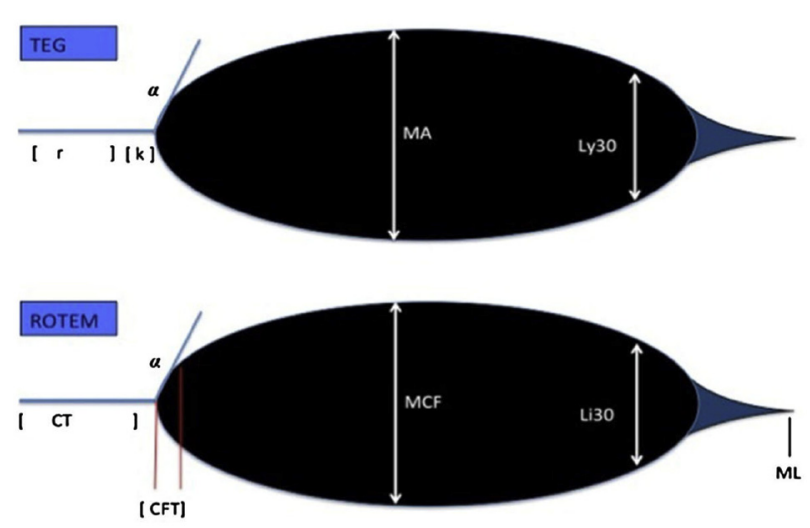

FIGURE 1. Thromboelastography versus rotational thromboelastometry, emphasizing the similarities between the 2 methods. Reprinted with permission from Simmons JW, Pittet J-F, Pierce B. Trauma-induced coagulopathy. Curr Anesthesiol Rep. 2014;4:189-99. 
cardiac surgery based on standard laboratory coagulation analysis $^{22}$ and on POC testing. ${ }^{17,18,23}$ The use of these algorithms has been associated with reduced transfusion and reduced stay in the intensive care unit. ${ }^{18}$

The described ROTEM-based algorithms differed in the parameters used for decision-making. For example, Nakayama and colleagues ${ }^{18}$ and Faraoni and colleagues ${ }^{23}$ predominantly used EXTEM (thromboelastometry with tissue factor) A10 and FIBTEM (thromboelastometry with cytochalasin D) A10, whereas Romlin and colleagues ${ }^{17}$ used FIBTEM MCF and HEPTEM (thromboelastometry with heparinase) MCF and CT. The A10 is the amplitude after 10 minutes, the MCF is the maximum clot firmness, and the $\mathrm{CT}$ is clotting time. These algorithms also differ in the hemostatic therapy administered in response to clinical bleeding and abnormal thromboelastometry values; some groups used all blood products, whereas others used factor concentrates.

\section{COAGULATION FACTOR CONCENTRATES}

Goal-directed therapy using POC testing with coagulation factor concentrate-based algorithms has been used safely and effectively to treat coagulopathy and reduce transfusion in adult cardiac surgery patients, ${ }^{21}$ but there are a paucity of data in children. Fibrinogen concentrate has been demonstrated to be as effective and safe as cryoprecipitate in children undergoing cardiac surgery, ${ }^{24}$ and fibrinogen concentrate is recommended for fibrinogen replacement in thromboelastometry-based transfusion algorithms ${ }^{17,23}$ for the treatment of postbypass coagulopathy in children. Recombinant activated factor VII has been used off-label in pediatric patients undergoing cardiac surgery to treat coagulopathy. The potential thrombotic risk associated with the drug should limit its use to rescue therapy for massive, refractory bleeding. ${ }^{25}$ The use of 3 -factor prothrombin complex concentrate (PCC) in 6 infants with ongoing bleeding after CPB has been reported by Jooste and colleagues. ${ }^{26}$ The risk of thrombotic complications is a concern with the use of factor concentrates; care should be taken to avoid the coadministration of rFVIIa and PCC containing factor VII.

\section{ANTITHROMBIN}

Heparin covalently binds to antithrombin, a glycoprotein that is made in the liver, and causes a 2000- to 4000-fold increase in thrombin inhibition, which enables systemic anticoagulation for CPB. There is significant variability in antithrombin levels in neonates, infants, and children that can be attributed to age, immaturity of the coagulation system, inflammation, and liver dysfunction. Patients with low levels of antithrombin have lower heparin efficacy, and more heparin is required to maintain an adequate ACT. In addition, lower antithrombin levels result in increased thrombin generation on $\mathrm{CPB}$, a risk factor for perioperative coagulopathy and/or thrombosis. ${ }^{27}$

In congenital heart surgery, antithrombin levels often are augmented by the administration of fresh-frozen plasma. Large volumes of fresh-frozen plasma, however, are required to increase the antithrombin level even modestly. Recombinant antithrombin is available in the United States and can be used specifically to increase antithrombin levels and improve heparin efficacy and decrease thrombin generation on CPB. Randomized controlled trials of preoperative antithrombin supplementation in adults undergoing cardiac surgery with the use of CPB have been published, and there has been one pilot study of antithrombin replacement in neonates undergoing CPB. ${ }^{28,29}$ Antithrombin replacement currently is used in pediatric patients on extracorporeal life support, and its use has increased heparin efficacy and reduced dosing in these patients. ${ }^{30}$

\section{COMMUNICATION}

Communication and teamwork is required for safe treatment for coagulopathy in pediatric cardiac surgery. POC testing, goal-directed transfusion algorithms, and factor concentrate availability improve the speed and efficiency of treatment of bleeding. However, a dialogue between the surgeon and anesthesiologist regarding the extent of bleeding, the presence of surgical bleeding, the results of POC testing, the status of clot formation, and the administration of blood products and and/or factor concentrates is critical to avoid undertreatment or overtreatment of coagulopathy with potential catastrophic thrombotic complications.

In addition, on arrival to the intensive care unit, a full assessment of the patient's hemostatic profile, including blood products given, intraoperative tests performed, and factor concentrates given, should be reported by the anesthesiologist to the entire intensive care team in a structured manner. The effective transfer of this information is necessary to avoid potentially life-threatening hypercoagulability and should be a standard element in the handover.

\section{POSTBYPASS BLEEDING IN NEONATES}

The avoidance and treatment of postbypass coagulopathy in the neonate continues to be a significant and pervasive challenge for those caring for patients undergoing congenital heart surgery. A greater risk of bleeding due to an immature coagulation system, large dilutional effect due to the volume of the CPB circuit compared with the neonatal blood volume, and often-complex operations with extensive suture lines and often performed at moderate to deep hypothermia. In a recent retrospective review of 169 neonates undergoing complex congenital heart surgery, patients in the upper quartile of postbypass bleeding had an increased risk of postoperative dialysis, extracorporeal membrane oxygenation, and in-hospital mortality. ${ }^{31}$ 
Avoidance of postbypass coagulopathy in neonates begins preoperatively. The bypass circuit can be miniaturized by the use of smaller-caliber and shorter bypass tubing, as well as a smaller oxygenator and hemofilter. Vacuumassisted drainage also can be used. These measures can decrease the amount of priming volume and therefore decrease the amount of dilution of coagulation factors. ${ }^{32}$ In addition, although there are institutional preferences and availability issues regarding the use of fresh whole blood or reconstituted whole blood for bypass circuit priming, ${ }^{6-9}$ it is critical for plasma to be added to the pump to maintain an adequate concentration of coagulation factors. The use of antifibrinolytic agents are warranted in this population, as well, to reduce the risk of fibrinolysis and the requirement for blood transfusion. ${ }^{1,33}$ POC testing such as ACT and ROTEM or TEG should be considered to guide blood product administration. Recombinant activated factor VII is not recommended for routine prophylaxis against bleeding in neonates undergoing congenital heart surgery, but it should be considered as rescue therapy after standard treatment has been carried out. $^{25,34,35}$ The Congenital Cardiac Anesthesia Society rFVIIa Task Force agrees on an initial dose of $90 \mu \mathrm{g} / \mathrm{kg}$ based on previous studies. ${ }^{25}$

Future directions in the prevention and treatment of postbypass coagulopathy in the neonate include intense heparin management with antithrombin level monitoring and replacement ${ }^{28,29,36}$ and the use of individualized anticoagulation management systems that have been shown to decrease blood product administration in infants undergoing cardiac surgery using $\mathrm{CPB} .{ }^{37}$ Although there is no evidence to support the use of newer factor concentrates such as 3- and 4-factor PCCs and fibrinogen concentrate in this population, ${ }^{34}$ there is ex vivo evidence that 3- and 4-Factor PCC augments thrombin generation in neonatal plasma after CPB and may be a useful adjunct to standard blood component therapy. ${ }^{38,39}$

The potential for creating a hypercoagulable state exists, and translocated coronary arteries and Blalock-Taussig shunts, for example, may be at risk. Care should be taken when administering these new medications. Combining PCCs and rFVIIa could create life-threatening thrombosis and, in our opinion, should be avoided. ROTEM, TEG, and/or standard coagulation laboratory tests should be followed.

\section{CONCLUSIONS}

Coagulation and transfusion management in pediatric cardiac surgery remain challenges in the care of these complex patients, and there is not one strategy that can be applied to every patient. With the multiple new monitoring tests and pharmacologic treatments for coagulopathy, additional research is needed to optimize the approach to the treatment of postbypass coagulopathy with both blood products and factor concentrates and to determine their effect on outcomes.

\section{Conflict of Interest Statement}

Authors have nothing to disclose with regard to commercial support.

\section{References}

1. Guzzetta NA. Benefits and risks of red blood cell transfusion in pediatric patients undergoing cardiac surgery. Pediatr Anesth. 2011;21:504-11.

2. Mahle WT, Tresler MA, Edens RE, Rusconi P, George JF, Naftel DC, et al. Allosensitization and outcomes in pediatric heart transplantation. J Heart Lung Transplant. 2011;30:1221-7.

3. Mahle WT, Berg AM, Kanter KR. Red blood cell transfusions in children awaiting heart transplantation. Pediatr Transplant. 2011;15:728-32.

4. Mazine A, Rached-D'Astous S, Ducruet T, Lacroix J, Poirier N, Pediatric Acute Lung Injury and Sepsis Investigators Network. Blood transfusions after pediatric cardiac operations: a North American multicenter prospective study. Ann Thorac Surg. 2015;100:671-7

5. Arnold P. Treatment and monitoring of coagulation abnormalities in children undergoing heart surgery. Pediatr Anesth. 2011;21:494-503.

6. Manno CS, Hedberg KW, Kim HC, Bunin GR, Nicolson S, Jobes D, et al. Comparison of the hemostatic effects of fresh whole blood, stored whole blood, and components after open heart surgery in children. Blood. 1991;77:930-6.

7. Jobes DR, Sesok-Pizzini D, Friedman D. Reduced transfusion requirement with use of fresh whole blood in pediatric cardiac surgical procedures. Ann Thorac Surg. 2015;99:1706-12.

8. Mou SS, Giroir BP, Molitor-Kirsch EA, Leonard SR, Nikaidoh H, Nizzi F, et al. Fresh whole blood versus reconstituted blood for pump priming in heart surgery in infants. N Engl J Med. 2004:351:1635-44.

9. Gruenwald CE, McCrindle BW, Crawford-Lean L, Holtby H, Parshuram C, Massicotte P, et al. Reconstituted fresh whole blood improves clinical outcomes compared with stored component blood therapy for neonates undergoing cardiopulmonary bypass for cardiac surgery: a randomized controlled trial. J Thorac Cardiovasc Surg. 2008;136:1442-9.

10. Eaton MP. Antifibrinolytic therapy in surgery for congenital heart disease. Anesth Analg. 2008;106:1087-100.

11. Ririe DG, James RL, O'Brien JJ, Lin YA, Bennett J, Barclay D, et al. The pharmacokinetics of $\varepsilon$-aminocaproic acid in children undergoing surgical repair of congenital heart defects. Anesth Analg. 2002;94:44-9.

12. Eaton MP, Alfieris GM, Sweeney DM, Angona RE, Cholette JM, Venuto C, et al. Pharmacokinetics of $\varepsilon$-aminocaproic acid in neonates undergoing cardiac surgery with cardiopulmonary bypass. Anesthesiology. 2015;122:1002-9.

13. Wesley MC, Pereira LM, Scharp LA, Emani SM, McGowan FX Jr, DiNardo JA. Pharmacokinetics of tranexamic acid in neonates, infants, and children undergoing cardiac surgery with cardiopulmonary bypass. Anesthesiology. 2015; 122:746-58.

14. Scott JP, Costigan DJ, Hoffman GM, Simpson PM, Dasgupta M, Punzalan R, et al. Increased recombinant activated factor VII use and need for surgical reexploration following a switch from aprotinin to epsilon-aminocaproic acid in infant cardiac surgery. J Clin Anesth. 2014;26:204-11.

15. Breuer T, Martin K, Wilhelm M, Wiesner G, Schreiber C, Hess J, et al. The blood sparing effect and the safety of aprotinin compared to tranexamic acid in pediatric cardiac surgery. Eur J Cardiothorac Surg. 2009;35:167-71.

16. Kane LC, Woodward CS, Husain SA, Frei-Jones MJ. Thromboelastographydoes it impact component transfusion in pediatric heart surgery. J Surg Res. 2016;200:21-7.

17. Romlin BS, Wåhlander H, Berggren H, Synnergren M, Baghaei F, Nilsson K, et al. Intraoperative thromboelastometry is associated with reduced transfusion prevalence in pediatric cardiac surgery. Anesth Analg. 2011;112:30-6.

18. Nakayama Y, Nakajima Y, Tanaka KA, Sessler DI, Maeda S, Iida J, et al. Thromboelastometry-guided intraoperative haemostatic management reduces bleeding and red cell transfusion after paediatric cardiac surgery. Br J Anaesth. 2015;114: 91-102.

19. Romlin BS, Wåhlander H, Synnergren M, Baghaei F, Jeppsson A. Earlier detection of coagulopathy with thromboelastometry during pediatric cardiac surgery: a prospective observational study. Pediatr Anesth. 2013;23:222-7. 
20. McEwan A. Aspects of bleeding after cardiac surgery in children. Pediatr Anesth. 2007; 17:1126-33.

21. Görlinger K, Shore-Lesserson L, Dirkmann D, Hanke AA, Rahe-Meyer N, Tanaka KA. Management of hemorrhage in cardiothoracic surgery. J Cardiothorac Vasc Anesth. 2013;27:S20-34.

22. Whitney G, Daves S, Hughes A, Watkins S, Woods M, Kreger M, et al. Implementation of a transfusion algorithm to reduce blood product utilization in pediatric cardiac surgery. Pediatr Anesth. 2013;23:639-46.

23. Faraoni D, Willems A, Romlin BS, Belisle S, Van der Linden P. Development of a specific algorithm to guide haemostatic therapy in children undergoing cardiac surgery. Eur J Aneasthesiol. 2015;32:320-9.

24. Galas FR, de Almeida JP, Fukushima JT, Vincent JL, Osawa EA, Zeferino S, et al. Hemostatic effects of fibrinogen concentrate compared with cryoprecipitate in children after cardiac surgery: a randomized pilot trial. J Thorac Cardiovasc Surg. 2014;148:1647-55.

25. Guzzetta NA, Russell IA, Williams GD. Review of the off-label use of recombinant activated factor VII in pediatric cardiac surgery patients. Anesth Analg. 2012;115:364-78.

26. Jooste EH, Machovec KA, Einhorn LM, Ames WA, Homi HM, Jaquiss RD, et al 3-Factor prothrombin complex concentrates in infants with refractory bleeding after cardiac surgery. J Cardiovasc Vasc Anesth. 2016;30:1627-31.

27. Gruenwald CE, Manlhiot C, Chan AK, Crawford-Lean L, Foreman C, Holtby HM, et al. Randomized, controlled trial of individualized heparin and protamine management in infants undergoing cardiac surgery with cardiopulmonary bypass. J Am Coll Cardiol. 2010;56:1794-802.

28. Andropoulos DB, Fraser CD Jr. Antithrombin levels during pediatric cardiopulmonary bypass: key to changing a decades-old paradigm for anticoagulation? $J$ Thorac Cardiovasc Surg. 2016;151:444-50.

29. Niebler RA, Woods KJ, Murkowski K, Ghanayem NS, Hoffman G, Mitchell ME, et al. A pilot study of antithrombin replacement prior to cardiopulmonary bypass in neonates. Artif Organs. 2016;40:80-5.

30. Ryerson LM, Bruce AK, Lequier L, Kuhle S, Massicotte MP, Bauman ME. Administration of antithrombin concentrate in infants and children on extracor- poreal life support improves anticoagulation efficacy. ASAIO J. 2014;60 559-63.

31. Guzzetta NA, Allen NN, Wilson EC, Foster GS, Ehrlich AC, Miller BE Excessive postoperative bleeding and outcomes in neonates undergoing cardiopulmonary bypass. Anesth Analg. 2015;120:405-10.

32. Chang HW, Nam J, Cho JH. Five-year experience with mini-volume priming in infants $\leq 5 \mathrm{~kg}$ : safety of significantly smaller transfusion volumes. Artif Organs. 2014;38:78-87.

33. Lin CY, Shuhaiber JH, Loyola H, Liu H, Del Nido P, DiNardo JA, et al The safety and efficacy of antifibrinolytic therapy in neonatal cardiac surgery. PLoS One. 2015;10:e0126514.

34. Puzalan RC, Gottschall JL. Use and future investigations of recombinant and plasma-derived coagulation and anticoagulant products in the neonate. Transfus Med Rev. 2016;30:189-96.

35. Pychynska-Pokorska M, Pagowska-Klimek I, Krajewski W, Moll JJ. Use of re combinant activated factor VII for controlling postoperative bleeding in children undergoing cardiac surgery with cardiopulmonary bypass. J Cardiothorac Vasc Anesth. 2011;25:987-94.

36. Manlhiot C, Gruenwald CE, Holtby HM, Brandão LR, Chan AK, Van Arsdell GS, et al. Challenges with heparin-based anticoagulation during cardiopulmonary bypass in children: impact of low antithrombin activity J Thorac Cardiovasc Surg. 2016;151:444-50.

37. Machovec KA, Jooste EH, Walczak RJ, Homi HM, Jaquiss RD, Lodge AJ, et al A change in anticoagulation monitoring improves safety, reduces transfusion, and reduces costs in infants on cardiopulmonary bypass. Pediatr Anesth. 2014; 25:580-6.

38. Guzzetta NA, Szlam F, Kiser AS, Fernandez JD, Szlam AD, Leong T, et al Augmentation of thrombin generation in neonates undergoing cardiopulmonary bypass. Br J Anaesth. 2014;112:319-27.

39. Franklin SW, Szlam F, Fernandez JD, Leong T, Tanaka KA, Guzzetta NA Optimizing thrombin generation with 4-factor prothrombin complex concentrates in neonatal plasma after cardiopulmonary bypass. Anesth Analg. 2016; 122:935-42. 